\section{Castration of piglets under general anaesthesia: a possible approach}

\section{Iwan Nussbaumer \\ Department of Clinical Veterinary Medicine, Swine Clinic, Vetsuisse Faculty, University Bern, Switzerland}

Since January 2010 the castration of piglets without pain relief has been forbidden in Switzerland. Swiss pig farmers now have two choices, either vet-performed anaesthesia and analgesia by intramuscular injection or farmer-administered isofluran anaesthesia by an inhalation device. Many smaller pig producers, with less than 60 sows, have chosen injected anaesthesia for economic, user safety and environmental reasons.

In 2006 Lahrmann et al. demonstrated the practicality of an intramuscularly administrated combination of azaperone $(2 \mathrm{mg} / \mathrm{kg}$ body weight) and ketamine (25 mg/kg body weight). ${ }^{1}$ Field reports from Swiss practitioners awakened doubts about the suitability of this combination. Reports such as disturbed sleep, inadequate surgical tolerance, psychomotor seizures upon awakening, and increased death rates, raised questions concerning animal welfare. The long sleep period diminishes suckling time, which may affect growth performance, and increases the risk of potentially fatal hypothermia. ${ }^{2}$

These effects are attributed to the large quantity of ketamine needed to reach a sufficient depth of anaesthesia. Methods that use reduced doses of ketamine should be researched.

Several combinations consisting of sedatives or neuroleptics ( $\alpha 2$-agonist or azaperone), opioids (butorphanol) and ketamine are proposed. ${ }^{3-6}$ Results from another field study have shown that a combination of azaperone (Stresnil, Janssen) at $5 \mathrm{mg} / \mathrm{kg}$ body weight, butorphanol (Dolorex, Intervet) at $0.2 \mathrm{mg} / \mathrm{kg}$ body weight and ketamine (Narketan, Vétoquinol) at $15 \mathrm{mg} / \mathrm{kg}$ body weight administered intramuscularly is suitable to reach a surgical tolerance of 20-30 minutes in young pigs (maximum 4 months old) with fewer undesired side effects. ${ }^{7}$

In this field trial the course of anaesthesia, the degree of surgical tolerance and the analgesic potency of the triple combination mentioned above was compared with the experiences made before with the combination of azaperone and ketamine without the addition of butorphanol. Increasing only the dose of azaperone and decreasing the dose of ketamine was not considered to be a succsessful way, because there was less analgesic potency expected by reducing ketamine, since it is well known that pigs need high doses of ketamine per kg bodyweight compared to other species. The unwanted effect, that piglets feel pain but could not move had to be avoided.

One hundred forty healthy male piglets from three different farms were anaesthetised by intramuscular injection into the neck muscles and then neutered by the farmer in the usual manner: Piglet lying on farmer's arm, the farmer presses the testicels into the scrotum with his fingers from the same hand holding the piglet. With the other hand a $1 \mathrm{~cm}$ long vertical incision over the testicel is made with a scalpell. Then the testicel is pulled out and the spermatic cord is cut. Same procedure with the other testicel.

In this trial eleven 10-14 days old piglets weighed 2.5 to $3 \mathrm{~kg}, 85$ three to four week old piglets weighed 4 to $8 \mathrm{~kg}$ and 44 already weaned, five to six week old piglets weighed 8 to $12.5 \mathrm{~kg}$ were anesthetized All pigs belonged to the same breed Edelschwein. The three farms were very similar in management, nutrition, farm size and housing conditions.

In this trial the piglets were at different age and number from each farm, because that reflects the conditions in practice: veterinarians would not come to the farm every week and anaesthetize a handful of piglets for castration. They visit the farm once in month and anaesthetize all piglets needing castration. So they will be several days old piglets and already weaned piglets as well. According to swiss law farmers are allowed to castrate piglets autonomous until they are 14 days old. They have to provide evidence of competence approved by officials. In case castration is performed under supervision of a veterinarian there is no need of approval and piglets may be older.

The quality of the anaesthesia was assessed using a simple observational scoring system with three different levels: excellent, good and fair (Table 1). The judgements were done all the time by the same person. Only pigs receiving excellent scores for all three categories introduction, surgery and recovery, were finally judged excellent. Pigs receiving only good in one or more category were classified as good. Having fair scores in one category would have been led to a fair judgement.

Before administering anaesthesia, piglets were clinically examined and weighed with a spring scale to allow dose of medicaments based on individual weight. Only healthy pigs were anaesthetised. After surgery, the suckling piglets were separated from their mothers and female siblings and placed in a warm nest until awakening. The castrated, weaned piglets (older than four weeks) were placed in a warm stable and also separated from other pigs until they were fully awake.

Five-ten minutes after drug administration an adequate depth of anaesthesia was achieved. After a maximum of two hours all
Correspondence: Iwan Nussbaumer, Im Rank 7 , 4800 Zofingen, Switzerland.

E-mail: iwannussbaumer@gmail.com

Key words: piglet, castration, pain relief, anesthesia, butorphanol.

Acknowledgements: great thank to the pig farmers that participated in this trial.

Conflict of interests: the authors report no conflict of interests.

Received for publication: 23 November 2011.

Revision received: 20 January 2012.

Accepted for publication: 20 January 2012.

This work is licensed under a Creative Commons Attribution NonCommercial 3.0 License (CC BYNC 3.0).

CC Copyright I. Nussbaumer, 2012

Licensee PAGEPress srl, Italy

Veterinary Science Development 2012; 2:e9

doi:10.4081/vsd.2012.e9

piglets were fully awake. No deaths or diseases could be attributed to the anaesthesia.

The vast majority, 121 pigs (86\%) experienced anaesthesia that was judged excellent during introduction, surgery and recovery. For 14 per cent of the pigs (19) the anaesthesia was judged good because of minor excitation during introduction and recovery or slight movements during surgery, which could be attributed to reflexes caused by tension applied to the spermatic cord. Surgery was feasible for all pigs due to sufficient depth of anaesthesia. Piglets under 14 days of age had tendency to show more movements during surgery. None of the piglets were scored fair.

Thus, by increasing azaperone in combination with a potent analgesic, therefore amplifying the sedative effects, the dose of ketamine and undesirable side effects can be reduced. The addition of butorphanol improves intraand postoperative analgesia, since ketamine has only a somatic analgesic effect and azaperone has no analgesic effect at all. ${ }^{8}$

Although no direct comparison to the azaperone/ketamine combination was performed in this study, the author's experience points to a significant improvement in anaesthesia when butorphanol is added. The fact that all piglets showed good or excellent scores and undesiderable effects like they were reported from practitioners and also experienced by the author using the combination azaperone/ketamine without butorphanol did not occur supports the argument that adding butorphanol and reducing ketamine leads to better anesthesia for the piglets. For animal welfare reasons a direct comparison of the two methods was not performed, because it was already 
Table 1. Description of the criteria to assess the quality of the anaesthesia during introduction, surgery and recovery.

\begin{tabular}{|c|c|c|c|}
\hline Score & Introduction & Surgery & Recovery \\
\hline Excellent & $\begin{array}{l}\text { Lies down quietly, does not } \\
\text { try to stand up again }\end{array}$ & $\begin{array}{l}\text { Muscles relaxed, } \\
\text { no movements }\end{array}$ & $\begin{array}{l}\text { Rests in sternal position } \\
\text { until able to stand, } \\
\text { no excitation }\end{array}$ \\
\hline Good & $\begin{array}{l}\text { Several trials to stand up } \\
\text { and walk around, reacts to } \\
\text { manipulation then lies } \\
\text { down and does not } \\
\text { react anymore }\end{array}$ & $\begin{array}{l}\text { Muscles relaxed, slight } \\
\text { movements when tension } \\
\text { on the funiculus is applied, } \\
\text { no other movements }\end{array}$ & $\begin{array}{l}\text { Several attempts to stand } \\
\text { up and walk before fully } \\
\text { able to stand, no excitation }\end{array}$ \\
\hline Fair & $\begin{array}{l}\text { Excitation, struggles, snores, } \\
\text { walks and crawls, then lies } \\
\text { down and does not react } \\
\text { anymore }\end{array}$ & $\begin{array}{l}\text { Slight muscle rigidity, } \\
\text { stronger movements when } \\
\text { tension on the funiculus } \\
\text { is applied, also other } \\
\text { movements during surgery }\end{array}$ & $\begin{array}{l}\text { Excitation, grunts and } \\
\text { snores, tries forcefully } \\
\text { to stand up and walk, } \\
\text { has a longer recovery time }\end{array}$ \\
\hline
\end{tabular}

known that with the combination azaperon/ ketamine losses of piglets will happen.

However, a disadvantage of both combinations is hypothermia, which occurs with the use of azaperone. It is therefore crucial that the piglets are kept warm after surgery until they are fully recovered. Most of the piglets in this trial were castrated at three weeks or older lowering the risk of anaesthetic incidents. Further disadvantages are the higher consumption of drugs, especially for older and heavier animals as well as the potentially delayed wound healing compared to animals castrated at a younger age. It is important to ensure that an emasculator is used in pigs older than 2 weeks because of the increased bleeding in anaesthetised rather than conscious pigs. Anesthetised piglets that are neutered bleed more due to atonic musculus cremaster and reduced constrictory ability of blood vessels when they are cut.

From a anesthetic viewpoint the optimal time for castration with injected anaesthesia is at the age of three weeks. However, economic reasons and a higher risk of delayed wound healing in older piglets may lead to the surgery being performed earlier in life.

\section{References}

1. Lahrmann KH, Kmiec M, Stecher R. Piglet castration with azaperone/ketamineanaesthesia concurring with animal welfare, practical, but economic ? Praktischer
Tierarzt 2006;87:802-9. [Article in German].

2. McGlone JJ, Hellman JM. Local and general anaesthetic effects on behaviour and performance of two and seven-week-old castrated and uncastrated piglets. J Animal Sci 1988;66:3049-58.

3. Nishimura R, Sakaguchi M, Mochizuki M, et al. A balanced anaesthesia with a combination of xylazine, ketamine and butorphanol and its antagonism by yohimbine in pigs. J Vet Med Sci 1992;54:615-20.

4. Sakaguchi M, Nishimura R, Sasaki N, et al. Anaesthesia induced in pigs by use of a combination of medetomidine, butorphanol and ketamine and its reversal by administration of atipamezole. Am J Vet Res 1996;57:529-34.

5. Brodbelt DC,Taylor PM. Comparison of two combinations of sedatives before anaesthetizing pigs with halothane and nitrous oxide. Vet Rec 1999;145:283-7.

6. Nussbaumer I, Peterbauer C, Zimmermann W. Anaesthesia of pigs with a combination of romifidine, butorphanol and ketamine. Vet Rec 2008;163:720-1.

7. Nussbaumer I, Leist Y, Peterbauer C, Zimmermann W. Clinical comparison of two intramuscularly injectable anaesthetic combinations for routine surgery in pigs. Proceedings 20th International Pig Veterinary Congress, Durban, South Africa, 22 to 26 June, 2008. p. 447

8. Plumb DC. Veterinary Drug Handbook. Pharma Vet Publishing, White Bear Lake, USA, 1999, p. 853. 